\title{
Organisational Factors Affecting Learning Transfer In The South African Public Service
}

\author{
Nditsheni Raliphada \\ Jos Coetzee \\ Wilfred I. Ukpere
}

\author{
Department of Industrial Psychology and People Management, \\ Faculty of Management, University of Johannesburg, Johannesburg, South Africa
}

E-mail: wiukpere@uj.ac.za

\author{
Doi:10.5901/mjss.2014.v5n2p743
}

\begin{abstract}
The purpose of the study was to identify organisational factors that affect learning transfer in the South African Public Service. The study was conducted using a mixed method approach. The study was conducted in one of the public service departments with a staff population of 3000 employees. A total of 5 managers were interviewed and 150 questionnaires were distributed, and a $60 \%$ response rate was achieved from the questionnaires distributed. Thematic content analysis was utilized to analyse qualitative data and descriptive exploratory factor analysis was utilized to analyse quantitative data. It was found that organisational factors such as organisational and performance culture, supervisor and management role, organisational policies and resource availability play a pivotal role in the ability of employees to transfer learning into the workplace.
\end{abstract}

Keywords: Department, Learning, Organization, Public Service, Transfer,

\section{Introduction}

The ultimate goal of all training and development initiatives rests in the ability of the trainees to implement the learned behavior, skills or techniques in the real life situation and for employees, it is the ability to apply newly acquired skills in the workplace. Research has been conducted in both public sector and private sectors to determine the return on investment of training and development initiatives. This study was prompted by the need to establish the root causes for failure of public servants to delivers services as expected by the South African communities. The study was premised on the assumption that the enactment of the Skills Development Act and Skills Development Levies Act is a reassurance that sufficient budget is allocated towards training and development initiatives for public servants. It is also premised on the understanding that the South African Quality Assurance Authorities assists in ensuring that quality programmes are delivered thus the need to identify factors within the organisation that may be affecting successful transfer of services as defined by the Batho Pele Principles.

The South African Public Service remains the largest provider of basic services in the country and following 19 years of post-apartheid government the country is growing impatient. A study on organisational factors affecting learning transfer is important as identification of this factors will assist public service leadership and Human resource development practitioners to develop strategies to address the challenges affecting learning transfer. Findings of this study suggests that organisational factors such as performance and organisational culture, resource availability such as time, supervisor and management roles as well as policies affect the ability of employees to implement what they have learned. It is interesting to note that although the studies were conducted in two separate countries South Africa and Jordan, the findings on factors affecting learning transfer do not differ significantly.

The current study is significant as it will provide a baseline for learning transfer studies both in private and public sector. Previous studies have indicated that there is room to explore factors affecting learning transfer. There is a general understanding that one cannot resolve what you do not know or acknowledge. Identification of factors affecting learning transfer is a critical step towards ensuring that successful strategies are developed to remove barriers to learning transfer and ultimately improve implementation which leads to enhanced service delivery.

This article will provide an overview of study that was conducted on organisational factors affecting learning transfer in public service environment. A summary will be provided of the research design as well as the findings or results of the study. 


\section{Objectives of the study}

The main objective of the study was to identify and describe organisational factors that affect learning transfer in the South African Public Service

The sub objectives were:

- To establish organisational factors that are hindering or inhibiting employees to transfer learning into the workplace

- To establish if there is a link between the organisational context and transfer of learning

- To determine the extent to which organisational factors affect learning transfer

- To identify the challenges that employees are facing that affect them in transferring what they have learned.

\section{Hypothesis}

The hypotheses provided relate to the quantitative methodology of the study.

$\mathrm{H} 1$ : Organisational factors such as peer support, management support and rewards, positively affect (encourage) the ability of employees to transfer learning in the public service if they are present and well managed.

$\mathrm{H} 2$ : The absence of organisational factors such as management support and peer support and rewards negatively affect (inhibit) learning transfer.

\section{Learning transfer}

It was important in this study to review the literature on studies that have been done with regard to the effect of organisational factors on learning transfer. The findings of previous studies will be discussed when findings of this study are presented. The transfer of learning into the workplace continues to be of significant value to organisation especially in the $21^{\text {st }}$ century which could be described as a knowledge economy error. Learning transfer is defined by Subedi (2004) as the degree to which trainees effectively transfer and apply the knowledge, skills and attitudes gained in the training environment to the work environment. According to Fuller, Munroe and Rainbird (2004) central to transfer of learning is increased knowledge, highly skilled performance and problem solving that enhances workplace productivity.

The ability of employees to transfer what they have learned into the workplace can be affected by various factors this may include organisational factors such as organisational culture and opportunity to transfer. Subedi (2004) identified factors that can affect learning transfer as the organisation's failure to provide support for skills retention, learner's lack of systematic procedure for identifying and coping with threats to learning transfer overtime.

Kontoghiorghes (2005) found that learning transfer can be enhance by the following factors; communication, information sharing, resource availability time, risk tolerance, opportunity for promotion and information availability. This study identified the organisational factors that affect learning transfer in the South African Public Service.

\section{Research design}

Creswell (2009) defined research design as plans and procedures that span decision from broad assumptions to detail methods of data collection and data analysis. It involves philosophies and strategies of inquiry that guide the study. This study has utilizes a mixed method approach.

\section{Philosophical foundations of mixed method}

According to Johnson and Onwuegbuzie (2004) the general characteristics of pragmatism include:

- the recognition of the existence and importance of natural or physical world and how it is influenced by language, culture, and subjective thoughts (perceptions)

- the recognition of the role of the organisation as a human institution, and 
- Rejects traditional dualism and adopts more moderate philosophical dualism of solving problems, preferring action rather than philosophising

- Endorses eclecticism and pluralism- different and conflicting theories and perspectives can be useful

- Instrumental truths are a matter of degree

- Provisional truth- views current truth, meaning and knowledge as tentative and changing overtime

This study followed a mixed method concurrent triangulation research approach as represented by the diagram below.

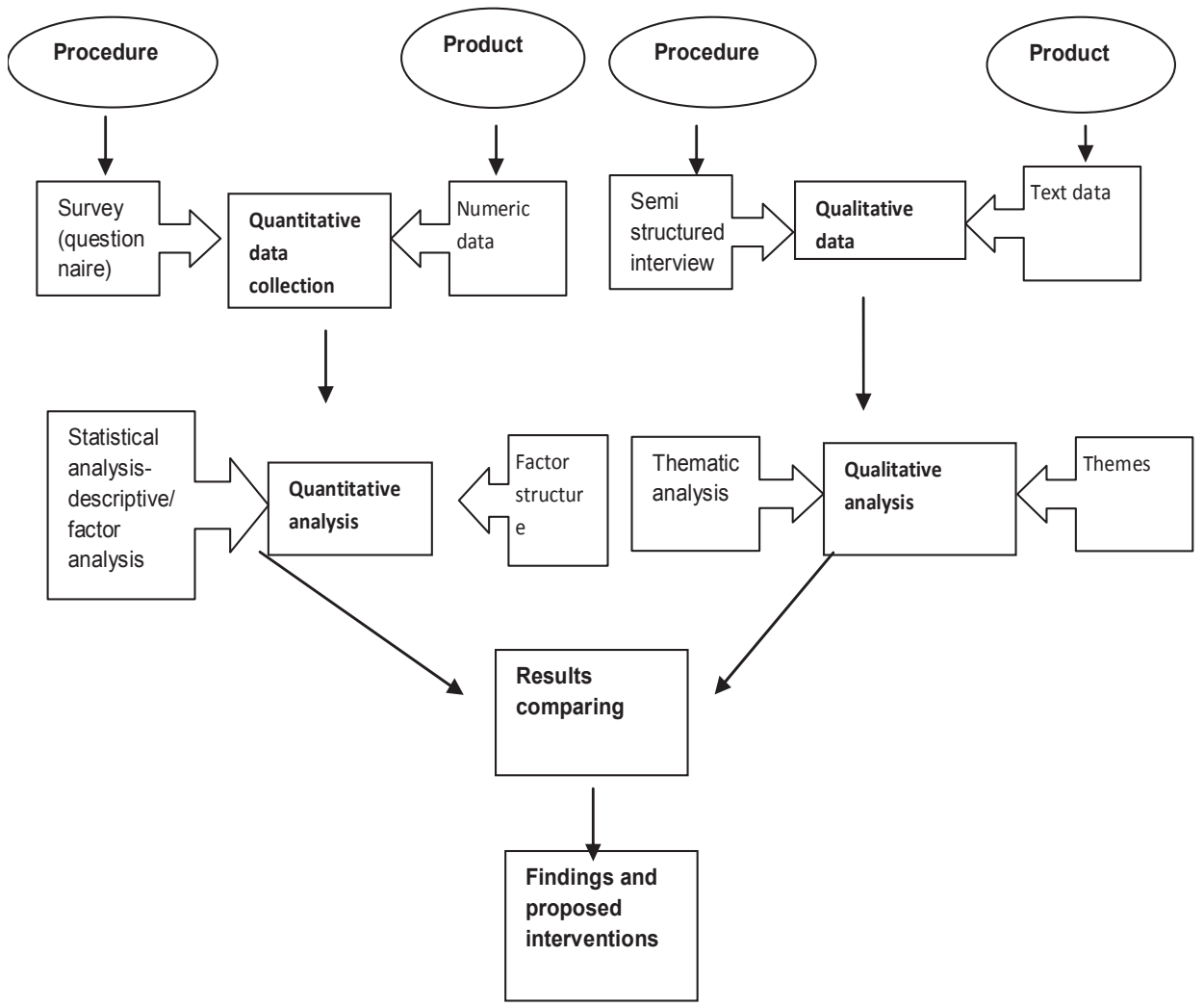

According to Onwuegbuzie and leech (2004) mixed method research design represent research that involves collecting, analyzing and interpreting quantitative and qualitative data in a single study or in a series of studies that investigate the same underlying phenomenon. Mixed method design use both inductive and deductive methods, has multiple forms of data collection that produces eclectic and pragmatic reports. In this study mixed method was deemed the most suitable for the following reasons:

- Public service represents complex organisations

- Mixed method enhances the strength of the research

- The use of mixed method ensured that the problem is explored from both perspectives (qualitative and quantitative)

- The usage of different approaches helped confirm data accuracy, complementing results from one type of the research approach with the other

In summary mixed method design was appropriate for this study as it neutralized and cancelled some of the disadvantages and limitations of either qualitative or quantitative methods. 


\section{Qualitative research}

The qualitative approach is grounded in the interpretive social sciences paradigm and it tends to be biased on recognition of the importance of a subjective, experiential worldview (Creswell and Plano Clark, 2007). The sampling size as outlined by Bartlett, Kotrlik and Higgins (2001) is determined by the research question and as study plans for qualitative research are iterative and flexible the sample size may change with the unfolding of the research. 5 managers were interviews utilizing semi structured interviews. Hockey, Robinson and Meah (2005) define a semi structured as a flexible interview which does not follow a formalized list of questions, instead the researcher has a list of general topics, called an interviewee guide. The advantages for using semi structured interviews are that difficult questions can be clarified, provides an opportunity for researcher to guide the interview as well as probe whenever necessary (David \& Sutton, 2004; Gray, 2004).

The Thematic Content Analysis (TCA) technique was chosen as it was best suited to the research question. Braun and Clarke (2006) referred to thematic analysis as a method for identifying, analyzing and reporting patterns (themes) within data". Charmaz (2006) refers to "theme" as the description of elements from text or data in an integrated and relational manner.

\section{Quantitative research}

The quantitative approach is grounded in the social sciences paradigm, which reflects the scientific method of the natural sciences (Creswell, 2008). This paradigm adopts a deductive approach and its main strength is precision and control The department had a total of +-3000 employees. A sample of 150 employees was randomly invited as respondents. A total of $60 \%$ of the respondents returned their questionnaires. $54 \%$ of people who responded to this study were females which represented the majority. All race groups as defined by the employment equity laws of the country were represented in the study.

Descriptive analysis was used to analyse data collected through survey questionnaires (quantitative). The rationale for choosing descriptive statistics is that it has added immeasurably to our knowledge of the shape and nature of society as good description helps us determine the facts and dimensions of the phenomenon. In this study Exploratory Factor Analysis (EFA) was used.

According to Darlington (2004) EFA is suitable in instances where a large number of variables are to be measured. It attempts to bring inter-correlated variables together and data is analyzed using multivariate statistical techniques. It is important for summarizing overall behavioral characteristics and the uniqueness of individual observation. The goal as indicated by Habing (2003) is to reduce the dimensionality of the original factors by interpreting new dimensions using latent factors.

As indicated by Malhotra (2004) reliability of research design in important for all studies. Reliability is said to refer to the extent to which scales produce consistent results when repeated at a later stage under similar conditions, Cronbach's alpha was used to determine the extent of agreement between respondents for each dimension. A higher score indicated a higher reliability with the range from 0-1. Validity which according to Golafshani (2003) may be viewed as the extent to which a particular measure is free from both systematic and random error could be reported as follows: The Kaiser Meyer Olkin (KMO) measure of sampling adequacy was 0.851 which is above 0.5 this meant that the data was adequate for analysis. Bartlett's test of sphericity was 1093.8.To ensure replicability of the study a clear account is provided in the subsections below of both qualitative and quantitative research design.

\section{Major findings}

\section{Interpretation of Qualitative findings}

In attempting to achieve the research objectives and demystify the hypotheses, the following themes were identified from the analysis of data:

\section{Resource Availability}

The business dictionary defines a resource as "an economic or productive factor required to accomplish an activity, or as a means to undertake an enterprise and achieve the desired outcome. The resources may include time, capital, labour, 
land, management information, etc.

Helfat and Peteraf (2003) refer to resources as assets that an organisation owns or accesses which enable the employee to achieve organisational goals. Resources when well utilized may increase the efficiency and effectiveness of an organisation which is one of the primary objectives of public service institutions.

Lack of resources like cars, telephones was cited as a hindrance in ensuring that employees implement what they have learned. It was indicated that lack of resources like cars makes it difficult for project managers to reach the communities that they are servicing, an example provided was that of an office with 10 project officers with only three cars which may result in poor supervision of projects as there will be minimal site visits. Barney (1991) indicated that the environmental context in which assets are applied for example the cars or telephones determine whether that asset is a resource or not. Insufficient funds to carry out new initiatives were cited as a factor that led to non-implementation of initiatives or innovations emanating from training interventions. An example was given where the procurement of new software would have enhanced the quality and turnaround times of services offered. The abilities of the new software had been demonstrated at a training session wherein the participant was exposed. On returning to the workplace a proposal was made to have the same software utilized by the Department, but due to lack of funds it could not be implemented. According to Katila and Shane (2005) financial resources influences innovation because access to capital allows the employee to follow through on their plan that would have emanated from exposure to training and development.

It can be inferred from the examples cited above that resource availability is critical to learning transfer. The organisation as the employer, supervisors, and human resource practitioners should plan for resources to be available post training interventions so that learning transfer can be supported and facilitated.

\section{Supervisor role}

A supervisor is defined by business dictionary as a person in the first-line management who monitors and regulates employees in their performance of assigned or delegated tasks. Supervisors are usually authorized to recommend and/ or effect hiring, disciplining, promoting, punishing, rewarding and other associated activities regarding employees in their departments. Kirwan (2009) identifies the role of supervisors as coach, mentor, advocate for organisation and advocate for employee. He further identified the responsibilities of a supervisor such as staffing, employee training and development and employee performance management (goals, delegating, feedback, and performance review among others).

All the participants highlighted the role that the supervisor can play in terms of either enabling or inhibiting learning transfer. It was further highlighted that lack of knowledge of what subordinates have been exposed to during the training interventions leads to the failure to buy-in to new initiatives by the supervisors. Employees already anticipate that they would not be supported even prior to them returning to their work stations, there is negative expectation on the side of subordinates which may affect the whole implementation process.

The readiness of supervisors to assume their role was also identified as one of the barriers to allowing learning transfer. According to the participant this may be caused by the supervisor having not gone through the ranks as well as lack of exposure in the new area that the subordinate was exposed to. The lack of knowledge on what the subordinate was trained on and is expected to implement leads to failure by the supervisor to follow up on learning transfer.

Participants also indicted that "supervisors just do not have interest" on the growth and development of subordinates. There was a sense of frustration that the researcher observed when participants shared this information. Supervisors are said to just allow employees to attend training programmes without understanding the course content and providing the necessary guidance. No effort goes into unpacking specific areas that the subordinate needs development so that proper monitoring can be carried out at a later stage

In addition to the fact that Supervisors lacked knowledge and understanding of areas that subordinates want to transfer their learning on, mistrust was cited as another barrier to learning transfer. Supervisors were said not to trust subordinates to allow them to independently execute their responsibilities "They are not willing to empower, they do not believe in empowerment". The supervisors were said to be inflexible, and subordinates are not given freedom to implement.

Nijman, Nijhof, Wognum and Veldkamp (2006) highlight the importance of supervisor support for learning transfer. They refer to supervisor support as behaviour exhibited by supervisor which optimizes employee's use of knowledge, skills and attitudes gained in training on the job, the support may be instrumental or emotional. In their qualitative study of environmental factors affecting transfer, Lim and Johnson (2002) found that supervisor involvement and familiarity with training, positive feedback and discussion on the use of learning are important for learning transfer. A positive 
relationship was found to exist between supervisor support and transfer of training (Cromwell \& Kolb, 2004 and Gumuseli \& Ergin, 2002).

In summary the relationship between supervisor and subordinates plays a pivotal role in unlocking potential for learning transfer. A positive relationship can lead to positive transfer whereas a negative relationship can lead to inaction on the part of the subordinate. Programmes for supervisors should be seriously considered if learning transfer is to be effective. Attributes of successful supervisors should be explored so that lessons thereof can be shard for enhancement of transfer of learning.

\section{Mentorship and coaching}

The participants reported that lack of mentorship and coaching as factors that may be affecting learning transfer. It was indicated that the willingness to coach and mentor is non-existent. Mentoring can be viewed as a developmental relationship between a more experienced individual, a mentor and a less experienced employee. The purpose of the mentoring process is for the mentee to receive guidance, share best practice in a less coercive environment. Coaching on the other hand is provided by the supervisor and is related to job performance.

Lim and Morris (2006) found that mentoring and coaching play a role in learning transfer. Swap, Leonard, Shields and Abrams (2001) found that mentor feedback is important for learning transfer although they concluded there is little evidence of direct relationship between mentoring and organisational performance. It can be inferred from the interviews conducted that there is minimal or no formal mentoring and coaching programmes in the department. A survey may be required for the department to gather information on employees' perception about mentoring and coaching and the value thereof. Coaching is a skill that should be harnessed and can be learned by supervisors. Support mechanisms especially exposure to coaching techniques might help supervisors in the organisation to execute their role with ease and this may also improve the success of learning transfer by subordinates.

\section{Role of Performance management}

Bersin and Associates (2005) define performance management as" management processes, which set measurable goals and objectives for employees, assess achievement and attainment of such objectives and then use this information to improve performance through coaching, compensation, training and other means.

The participants indicated that there is no follow up on implementation after training. They indicated that monitoring is not done in the department. There is no checklist post training and as managers they are not empowered to follow up on whether training has improved performance or not. It was observed that there is lack of ownership by managers in terms of their role with regard to impact assessment of training and development initiatives. The participants would say "there is no impact analysis template to monitor change after training.Participants indicated that supervisors are not genuinely engaging in performance review sessions; this makes it difficult to identify accurately the employees gaps, so that employees can be referred for correct interventions. No discipline measures taken for nonperformance. Managers are afraid to take decisions on non-performing employees

Fuller et al (2004) indicated that highly skilled performance and ability to enhance productivity in the workplace are demonstration that learning transfer has taken place. It can be inferred that skills transfer is being inhibited by the failure of the organisation to recognise the link between both individual and organisational performance and learning transfer. In their study Argote, Ingram, Levine and Moreland (2000) found that there is a link between knowledge transfer and individual performance in the organisation. The department needs to incorporate training and development initiatives into employees' performance contracts; this will improve the management and monitoring of learning transfer.

\section{Non alignment of training programmes with organisational goals}

Generic training reduces employee's productivity level. The over-emphasis of generic training makes it difficult for employees to implement. Employees are exposed to loose courses like your excel and project management, this is not to say they are not important. However, the employees on coming back do not have to pursue the implementation of generic courses as it does not directly increase productivity in their line of work. It becomes training for certification.

Non alignment of training and job outputs and performance indicators makes it difficult for learning transfer. The training provided is said not to be practical in most of the instances. It can be inferred that the misalignment between training received and its relevancy to the organisation inhibits learning transfer. It will be beneficial for the organisation to 
ensure that mechanisms are put in place to expose employees to training programmes that have practical impact on the day to day activities of the organisation. Training for impact and not training for activity in order to submit the annual training report as required by the Skills Development Act.

\section{Poor organisational planning and weak controls}

The role played by the organisation prior training and development intervention was discussed at length by participants. The importance of skills audit and training needs analysis as well as identification of gaps was seen as one way of ensuring that employees receive targeted training which leads to achievement of objectives. The inability of human resource training and development unit to conduct skills audit and provide report to guide supervisors on skills gap was seen as an inhibitor to learning transfer. It was explained by participants that due to lack of skills audit supervisors do not have grounds to restrict subordinate to go on courses, thus employees end up attending irrelevant courses that are not implementable when they come back to the workplace. "Manager just allows subordinates to attend any course". There is reasonable suggestion that learning transfer is not planned and what cannot be planned for cannot be measured. This may be related to why there is unreliable report on return on investments on training initiatives. Human resource practitioners need to plan for learning transfer and also measure success implementation thereof.

\section{Management and leadership change}

The participants highlighted that the constant change in management and leadership is creating a challenge for learning transfer. Employees get exposed to a training intervention with "current" management, following the current plans and by the time they complete the training programme and are required to implement, there is a new manager, with new plans and the acquired skills are said to be irrelevant. "all new managers want to bring in new plans and ways of doing things without even testing the effectiveness of the current ones" .

The other hindrance that was raised in this regard involved displacement of staff when management changes. It was reported that when new management joins the department they choose new teams and render other employees redundant or "supernumerary", this action meant that the employees cannot implement what they have learned and their skills are made dormant. It was said that this creates feelings of self-doubt to employees and affects their morale, which affects their ability to implement newly learned skills.

Clarke (2002) found that management support is perceived by employees as critical for learning transfer. It can be inferred that lack of management support and constant change in leadership is affecting learning transfer. Consistency in leadership creates a familiar environment which gives employees confidence and provides assurance when trying new behaviour.

\section{Resistance to change}

Holton, Bates and Ruona (2000) define resistance to change as "the extent to which prevailing group norms are perceived by individuals to resist or discourage the use of skills and knowledge acquired in training. It was indicated that supervisors are rigid. It was also cited that familiarity becomes a challenge, the supervisor and managers will say "we have been doing this thing for so many years, there is no need to change, it is working". It was also indicated that sometimes resistance is triggered by fear that if the subordinate is given opportunity to implement and the project is a success it may reduce the importance of the supervisor. Supervisors also fear job loss as they think ability of subordinate to implement means they can be replaced easily.

The government bureaucracy or protocol was cited as reason for refusal to adapt into new ways of doing things. The departmental staff always hides behind protocol and the available structures of authority to resist new ways of doing things. I can be inferred that resistance to change is one of the factors that hinder learning transfer in the public service. It is proposed that change management programmes be implemented to prepare teams in divisions for new changes. The resistance to change may be attributed to insecurity associated with high levels of job losses and unemployment both in the country and globally. Protectionism of current jobs may be the reason for blocking any new initiatives and the department should further investigate the matter as it may not only affect learning transfer but may affect the growth of the organisation and its ability to remain relevant in the changing global environment. 


\section{Organisational culture}

Participants indicated that some of the barriers to implementation include a culture of dictatorship. Experts are not provided opportunities to practice according to their professional standards, principles and policies. Instructions are just given and most of the time the instructions are contrary to what professional standards require. Employees are not allowed to think or execute as per their functional area. A new culture that has developed that is hindering learning transfer is the recruitment of less competent people. Employees who were in the organisation longer and had required competencies to occupy the advertised position simply stop making any effort to perform, or implement as per their training.

The culture of favouritism in the organisation is also playing its role in discouraging employees who were exposed to training to transfer what they have learned as suported by Kreitner and Kinicki (2001) views of organisational culture as a set of shared, taken for granted implicit assumptions that a group holds, thinks about and reacts to and mostly not documented. Organisational culture can be viewed to be inhibiting learning transfer in this department and this may also be due to the bureaucratic nature of the South African public service.

\section{Interpretation and synthesis of Quantitative results}

\section{Opportunity to practice}

There is a high correlation between learning transfer and opportunity to practice. In a study conducted by Scott (2010) it was found that employees are more likely to transfer learning if the opportunity is provided. In their responses to the role of policy in ability to transfer it was found that there is a high relationship between learning transfer and the policy environment. It can be inferred that conducive policy environment should be created by the organisation in order to encourage transfer of learning, policies should be audited and reviewed to determine their suitability for learning transfer, where possible as proposed by McDonnell, Gunnigle and Lavelle (2010) and Tregaskis, Glover and Ferner (2005) learning transfer policies should be developed.

Opportunity to practice could also be influenced by existing processes within the organisation. More than $60 \%$ of the employees indicate that there is a relationship between learning transfer and organisational processes. It can be inferred that relevantly aligned processes may improve learning transfer. The design of the organisation as well as the placement of the employee in the organisation can afford or hinder the employee to transfer what they have learned. Sambrook and Stewart (2000) found that organisational structure and job design influence an organisation's learning culture. Ashton (2004) found that learning transfer can be shaped by organisational decisions, provision and access that may be largely influenced by the position of the employee in the organisation which is referred to as placement. In this study the majority of employees reported that to a large extent the organisational structure and the placement of employees affect their ability to practice what they have learned. It can be inferred that opportunity to practice which in this study can be said to influence by a combination of policies, organisational structure, and placement of employee within the organisation affect learning transfer.

\section{Peers and Positional power}

Peer support according to Kirwan (2009) involves openness to new ideas by colleagues, provision of practical assistance like filling in for colleagues while they are committed elsewhere and their views on experimentation and willingness to learn new things. It was found by Cromwell and Kolb (2004) and Kirwan (2009) that peers may influence learning transfer depending on the level of interdependency. Enos, Kehrhahn and Bell (2003) found that there is little correlation between support and training transfer.

In this study it was found that peer support has moderate influence on learning transfer. It was also established that the employee's position in the organisation affect learning transfer. Employees who hold positions with authority and decision making powers stand a better chance of transferring learning as they are decision makers. Employees who are in less decision positions do not enjoy a similar advantage as their implementation plans have to be ratified and this may affect their ability to transfer what they have learned. 


\section{Resource availability}

In their study Holton, Voller, Schofield and Devine (2010) found that learning transfer is undermined by factors such as work pressures, staff culture that resist change and lack of support from line managers. A relationship was found to exist between availability of funds and the ability to practice what was learned. Ronen (2008) found that workload has an impact on transfer of learning. In this study $60 \%$ of the employees indicated that their current workload provides them the opportunity to transfer learning.

Time is a valuable resource when one is required to implement new techniques that were acquired from training initiative. This study found that a relationship exists between learning transfer and time with $26 \%$ of employees reporting that time is less significant in their ability to transfer learning. Waller (2012) found that time may be one of the biggest barriers to applying learning, it was reported that when employees return to work post training interventions pressure of heavy workloads made it difficult to find time to try out new ways of working.

It can be concluded that the necessary time to reflect on what employees have learned, good mental space and less distractions at work the probability of learning transfer is increased. It was found in this study that availability of funds affect learning transfer.

\section{Performance culture}

The majority of the employees in the department understand that there is a link between learning transfer and job performance within the organisation, they further recognize that their ability to perform will result in valued outcomes for their customers which are service recipients and communities to be specific.it was interesting to note that there was a split on the extent to which formal and informal performance indicators reflect training acquired. Rice (2007) found that a high performance culture may positively impact employee engagement by providing for meaning and connection to organisational goals a as well as encourage innovation, risk taking and trust. Organisations should invest in change management initiatives in order to instill a high performance culture in the organisation.

\section{Management support}

Axtell, Holman, Unsworth, Wall and Harrington (2000) found that employees with more supportive managers are more likely to implement what they have learned. There was a fair split on the extent to which broader management affect the ability of employees to implement what they have learned. This may be a good area for follow up research to be done to determine the impact of broader management on learning transfer. It is further interesting to note that the respondents felt very strongly that the employees' ability to transfer learning is largely affected by management who are autocratic and also when there are constant changes of management in the organisation.

\section{Reward and feedback}

The respondents indicated that innovation is rewarded only to a small extent; one can infer that employees do not get motivated to implement what they have learned as there are no incentives associated with innovative behaviour. Myers (2009) found that feedback and performance coaching positively affected learning transfer. $60 \%$ of employees in this study indicated that they received feedback whereas $32 \%$ indicated that they did not receive feedback. This study established that a relationship does exist between learning transfer and reward and feedback but a causal study need to be conducted to determine causal factors.

It is interesting to note that political interference did not seem to play a prominent role in affecting learning transfer and the study by Holton et al (2010) had the same findings. The current study corroborated those findings as $70 \%$ of the respondents in the survey indicated that political appointees affect their ability to transfer learning to a very small extent or to no extent at all.

It was further found in this study that monitoring mechanisms set in the organisation process by the organisation play a role in the ability of employees to transfer learning acquired during training interventions. Factors like the conducting of gap analysis prior to employee attending training intervention were seen to be overlooked in the organisation. It was further found that the organisation never requires proof of any form of certification post training. It is my opinion that when post training monitoring mechanisms are not clearly spelled out to employees they may not feel challenged to implement. Lack of incentive for learning transfer was one of the areas that employees felt that department 
is not focusing on. It can be inferred that the organisational context plays a pivotal role in the ability of employees to implement what they have learned post-training. This study has demonstrated that contextual factors like policies and performance culture of the organisation can be enabling factors for learning transfer if well managed.

It was interesting to note the variance in the percentage to which participants expressed their observation of the extent to which learning transfer to the workplace is occurring, some indicated the probability of learning transfer within the organisation is $1-2 \%$, others indicated it is $25-30 \%$ whereas others indicated it is $45 \%$. The participants in the study all agreed to the fact that the organisation does not have impact assessment processes in place. The organisation from a formal perspective does not have the knowledge of the extent to which organisational factors are affecting training

\section{Data Integration}

From the qualitative and quantitative finding it can be concluded that there is corroboration of findings, which have strengthened the outcome of this study. It further justifies the validity of the mixed methods as a suitable approach for researching a research problem as stated initially.

\section{Limitations and directions for future research}

In this study concurrent mixed method approach was adopted and it strengthened the findings of the study and two groups participated. Sequential studies can be done with the same group in future studies. However possible limitations to this study may include:

Self-reporting- In this study employees and managers were requested to report on their own perception which may not necessarily be factual. No post confirmation was done with respondents and participants to crosscheck if the findings of the study verify their perceptions.

Sample size- The study was conducted in only one department whereas the country has 27 national departments and thus one cannot comfortably generalise the findings of the study to the whole of South African Public Service.

Questionnaire- The questionnaire was designed based on literature review, it was close ended and did not give respondents an opportunity to raise other factors that may not have been originally included. In future opportunity should be provided to include additional information or factors

Future studies should focus on longitudinal case studies that unpack how learning transfer took place and encourage people to diarize their experiences in this regard. Valuable lessons can be learned from case studies through diarizing as for most people learning transfer occurs unconsciously. The questionnaire should give opportunity for respondents to provide additional information, if available. Based on new factors that were identified from semi structured interviews the questionnaire should be revisited to include new factors. Factor specific studies should be conducted to establish further understanding of the organisational factors affecting learning transfer

\section{Conclusion}

The successful identification of factors affecting learning transfer may assist public service management to develop interventions that will remove or minimize barriers hindering transfer in instances where non-transfer is occurring. It is also essential to identify positive factors affecting learning transfer so as to encourage the creation of a conducive environment that will yield better returns for investment done through training. The findings of this study should be a valuable contribution to the understanding of the factors that affect learning transfer in the public service. The knowledge gained could help departments to create conducive environments to improve learning transfer.

\section{References}

Argote, L., Ingram, P., Levine, J.M., \& Moreland, R.L. (2000). Knowledge transfer in organisations:Learning from experiences of others. Organisational Behaviour and Human Decision Process, 82, 1-8.

Ashton, D. N. (2004). The impact of organisational structure and practices on learning in the workplace. International Journal of Training and Development, 8 (2), 43-53. 
Axtell, C., Holman, D., Unsworth, K., Wall, T., Waterson, P., \& Harrington, E. (2000). Shopfloor innovation: Facilitating the suggestions and implementation of ideas. Journal of Occupational and Organizational Psychology, 73, 265-285.

Barney, J. (1991). Firm resources and sustained competitive advantage. Journal of Management, 17(1), 99-120.

Bartlett, J. E. II, Kotrlik, J. W., \& Higgins, C. C. (2001). Organisational research: Determining appropriate sample size in survey research. Information Technology, Learning and Performance Journal, 19 (1), 43-51.

Bersin and Associates. (2005).The convergence between learning and performance management systems. Retrieved October 2012 from http://www.bersinassociates.com.

Braun, V., \& Clarke, V. (2006). Using thematic analysis in psychology. Qualitative Research in Psychology, 3 (2), 77-101.

Charmaz, K. (2006). Constructing grounded theory: A practical guide through qualitative analysis. Thousand Oaks California: Sage

Clarke, N. (2002). Job-work environment factors influencing transfer within a human service agency. International Journal of training and Development, 6 (3), 146- 162.

Creswell, J. W. (2008). Educational research: Planning, conducting and evaluating quantitative and qualitative research. Upper Saddle River, NJ: Pearson.

Creswell, J. W. (2009). Research Design: Qualitative, Quantitative and mixed methods approached (2nd ed.). Thousand Oaks, California: Sage.

Creswell, J. W., \& Plano Clark, V. L. (2007). Designing and conducting mixed methods research. ThousandOaks, California: Sage.

Cromwell, S. E., \& Kolb, J. A. (2004). An examination of work environment support factors affecting transfer of supervisory skills training to the workplace. Human Resource Development Quarterly, 15 (4), 449-471.

David, M., \& Sutton, C. D. (2004). Social Research: The Basics. London: Sage.

Enos, M. D., Kehrhahn, M. T., \& Bell, A. (2003). Informal learning and the transfer of learning: how managers develop proficiency. Human Resource Development Quarterly, 14 (4), 369-387.

Fuller, A., Munro, A., \& Rainbird, H. (2004). Workplace learning in context. London: Routledge.

Golafshani, N. (2003). Understanding reliability and validity in qualitative research. The Qualitative Report, 8 (4), 597-606. Retrieved 10 July 2012 from http://www.nova.edu/ssss/ar/qr8-4/golafshani

Gray, D. E. (2004). Doing Research in the Real World. London: Sage.

Gumuseli, A. I., \& Ergin, B. (2002). The manager's role in enhancing the transfer of training: A Turkish case study. International Journal of Training and Development, 6 (2), 80-97

Habing, B. (2003). Exploratory factor analysis. Retrieved from http://www.stat.sc.edu/habing/course/530/course.

Helfat, C. E., \& Peteraf, M. A. (2003). The Dynamic resource-based view: capability lifecycles. Strategic Management Journal, 24, 9971010.

Hockey, I., Robinson, V., \& Meah, A. (2005) Cross generational investigation of the making of heterosexual relationships, $1912-2003$. Colchester, Essex: UK data archive.

Holton, E. F., Bates, R. A., \& Ruona, W. E. A. (2000). Development of a Generalized Learning Transfer System Inventory. Human Resource Development Quarterly, 11(4), 333-358.

Holton, V., Voller, S., Schofield, C., \& Devine, M. (2010). Improving learning transfer: a pilot study with three Ashridge client organisations. Retrieved from $\mathrm{Http}: / /$ www. ashridge.org.uk.

Johnson, R. B., \& Onwuegbuzie, A. J. (2004). Mixed methods research: A research approach whose time has come. Educational Researcher, 33 (7), 14-26.

Katila, R., \& Shane, S. (2005). When does lack of resources make new firms innovative? Academy of Management Journal, 48 (5), $814-$ 829.

Kirwan, C. (2009). Improving learning transfer- a guide to getting more out of what you put into your training. England: Gower.

Kontoghiorghes, C. (2005). Examining the relationship between learning organisation characteristics and change adaptation, innovation and organizational performance. Human Resource Development Quarterly, 16 (2), 185-212.

Kreitner, R., \& Kinicki, A. (2001). Organisational Behaviour (5th ed.). Boston: McGraw Hill.

Lim, D. H., \& Johnson, S. D. (2002). Trainee perceptions of factors that influence learning transfer. International Journal of Training and Development, 6 (1), 36-48.

Lim, D. H., \& Morris, M. L. (2006). Influence of trainee characteristics, instructional satisfaction and organisational climate on perceived learning and training transfer. Human Resource Development Quarterly, 17 (1), 85-115.

Malhotra, N. K. (2004). Marketing research: An applied orientation (4th ed.). New Jersey: Pearson Education.

McDonnell, A., Gunnigle, P., \& Lavelle, J. (2010). Learning transfer in multinational companies: explaining inter-organisation variation. Human Resource Management Journal, 20 (1), 23-43

Myers, M. J. M. (2009). Transfer of learning from training program to the workplace in a university health care organisation setting. Doctoral dissertation paper.www.digitalcommons.uconn/edu/dissertations/aa13391699.

Nijman, D. J. J. M., Nijhof, W. J., Wognum, A. A. M., \& Veldkamp, B. P. (2006). Exploring differential effects of supervisor support on transfer of training. Journal of European industrial training, 30, 529-549.

Rice, C. (2007). Driving long term engagements through a high- performance culture. Princeton: Blessing white,

Ronen, E. (2008). Transfer of e-learning in the workplace: the effects of trainee characteristics and contextual factors. Retrieved December 2012 from www.dl.acm.org.

Sambrook, S., \& Stewart, J. (2000). Factors influencing learning in European learning oriented organizations: Issues of management. Journal of European Industrial Training, 24 (2), 209-219. 
Scott, L. (2010). A study on the relationship between ability, motivational and work environment influences and the degree of transfer of learning for new trainees. Proquest database. No. 518000.

Subedi, B. S. (2004). Emerging trends of research on transfer of learning. International Education Journal, 5 (4), 591-599.

Swap, W., Leonard. D., Shields, M., \& Abrams, L. (2001). Using mentoring and storytelling to transfer knowledge in the workplace. Journal of Management Information Systems, 18 (1), 95-114.

Tregaskis, O., Glover, L., \& Ferner, A. (2005). International HR Networks. London: CIPD.

Waller, L. (2012). Enhancing the transfer of learning: A focus on the individual 360 The Ashridge Journal,34-41.Retrieved from http://www.ashridge.org.uk/website/content.nsf/w360/2012 spring transfer 